\title{
HAEMODYNAMIC AND CATECHOLAMINE RESPONSE TO ISOFLURANE ANAESTHESIA IN PATIENTS UNDERGOING CORONARY ARTERY SURGERY
}

\author{
Kanteerava Balasaraswathi, Silas N. Glisson, Adel A. El-Etr and \\ Nagaprasadarao MuMManenI
}

\begin{abstract}
Haemodynamic and plasma catecholamine responses were evaluated during isoflurane anaesthesia in ten patients undergoing coronary artery bypass surgery. Following thiopentone induction the patients were anaesthetized with isoflurane 1.5-2.0 per cent in oxygen. The results show that after 10 minutes of isoflurane anaesthesia there was a significant increase from baseline in heart rate, 68 to 80 ; cardiac output, 3.75 to 4.61 ; and plasma epinephrine, 0.80 to $1.33 \mu \mathrm{g} / \mathrm{l}$. Conversely, there was a significant reduction in systemic vascular resistance index, 3388 to 2260 , and plasma norepinephrine, 1.10 to $0.88 \mu \mathrm{g} / \mathrm{l}$. Twenty-five minutes later, after sternotomy, heart rate, cardiac output and the level of plasma epinephrine were still elevated, and systemic vascular resistance index and plasma norepinephrine remained lowered $(p<0.05)$. This study demonstrates significant catecholamine responses during isoflurane anaesthesia. The increase in plasma epinephrinc paralleled the increase in heart rate and cardiac output, and the decrease in plasma norepinephrine paralleled the decrease in systemic vascular resistance. Based upon these findings we conclude that catecholamine responses contribute to the cardiac and peripheral cardiovascular changes observed with isoflurane anesthesia.
\end{abstract}

Key Words: Anaesthetics, Volatile, isoflurane; AnaEsthesia, cardiovascular; SyMPATHETIC NERvous SySTEM, catecholamines, epinephrine, norepinephrine. HAEMODYNAMICS.

\section{INTRODUCTION}

ALTHOUGH SEVERAL STUDIES have investigated the haemodynamic responses that occur in man with isoflurane, few have investigated the effect of isoflurane on sympathoadrenal activity. Cardiac output is reported to be adequately maintained with concentrations of isoflurane which are used clinically, although sufficiently high concentrations of isoflurane will depress the heart. ${ }^{1-3}$ Stevens, et al. ${ }^{1}$ reported that cardiac output is sustained with isoflurane by an increase in heart rate that compensates for a concomitant

Kanteerava Balasaraswathi, M.D., Associate Professor; Silas N. Glisson, Ph.D., Associate Professor; Adel A. El-Etr, M.D., Professor and Chairman; Nagaprasadarao Mummaneni, M.D., Clinical Assistant Professor: Department of Anesthesiology, Stritch School of Medicine, Loyola University Medical Center, Maywood, Illinois 60153, U.S.A.

Correspondence and reprint requests to: Silas

N. Glisson, Ph.D., Department of Anesthesiology, Loyola University Medical Center, 2160 South First Avenue, Maywood, Illinois 60153, U.S.A.

Isoflurane (Forane) supplied courtesy of Ohio Medical Products.

533

reduction in stroke volume. It was suggested that this increase in heart rate, as well as a decrease in peripheral resistance results from beta-adrenergic stimulation by isoflurane. Other studies also have suggested that isoflurane has beta receptor activity, although the degree of stimulation was considered to be much less than that demonstrated for other anaesthetic agents. ${ }^{2,4}$ Philbin and Lowenstein ${ }^{5,6}$ were unable to demonstrate any central beta-adrenergic effect of 1 MAC isoflurane in the presence of profound beta blockade in the dog. Isoflurane did cause moderate changes in peripheral vascular resistance, suggestive of a peripheral beta stimulating action. Higher concentrations of isoflurane were used in a second study, but the results still did not demonstrate a clinically important cardiac betaadrenergic action of isoflurane. The actions of isoflurane on cardiovascular reflexes in cats were investigated by Skovsted and Sapthvichaikul. ${ }^{7}$ These authors concluded that the cardiac responses occurring in the presence of isoflurane represented an imbalance between autonomic sympathetic and parasympathetic influences on the heart. Isoflurane caused depression of both

Can. Anaesth. Soc. J., vol. 29, no. 6, November 1982 
preganglionic sympathetic and vagal nerve activity, with the greater effect on the vagus. The authors suggested that the vagal depression, in conjunction with the reported stimulatory beta effects, was responsible for the tachycardia observed during isoflurane anaesthesia.

To investigate the cardiovascular responses to isoflurane further a study was conducted to determine if sympathoadrenal activity is influenced by isoflurane as reflected by changes in the level of plasma epinephrine and norepinephrine in patients undergoing coronary artery bypass surgery.

\section{Patients and Methods}

Ten patients with ischaemic heart disease who were scheduled to undergo coronary artery bypass surgery were included in the study. Informed consent was obtained which had the approval of the Institutional Review Board. All the patients had an ejection fraction of over 0.60 and were taking propranolol $160 \mathrm{mg}$ daily and isosorbide dinitrate $50 \mathrm{mg}$ daily. The last dose of propranolol was given six hours before operation.

Morphine $0.1 \mathrm{mg} \cdot \mathrm{kg}^{-1}$ was given intramuscularly one hour before operation. In the operating room, two peripheral veins, a radial artery and the right internal jugular vein were cannulated under local anaesthesia. A triple lumen thermistor-tipped Swan-Ganz catheter was satisfactorily positioned in the pulmonary artery. Following cannulation the patients remained quiet for 10 minutes while breathing oxygen at a flow rate of $5 \mathrm{l} /$ minute by mask. Pre-induction arterial blood samples for catecholamine levels were then drawn and the following baseline haemodynamic values were obtained: heart rate, mean arterial pressure, right atrial pressure, mean pulmonary artery pressure, pulmonary capillary wedge pressure, cardiac output (values were averaged from three determinations) stroke volume, systemic vascular resistance index and stroke work index.

Anaesthesia was induced with thiopentone $6 \mathrm{mg} \cdot \mathrm{kg}^{-1}$ given as an intravenous infusion in one per cent solution over a period of five minutes. Immediately following the loss of lid reflex, pancuronium $120 \mu \mathrm{g} \cdot \mathrm{kg}^{-1}$ was administered and the patients were ventilated with isoflurane $1.5-2$ per cent in oxygen and the trachea was intubated within five minutes. Additional arterial blood samples were drawn for catecholamine analysis and the haemodynamic parameters were recorded ten minutes after isoflurane was begun and five minutes after median sternotomy. Arterial blood gases were monitored and body temperature was maintained at $36 \pm 0.5^{\circ} \mathrm{C}$. Plasma epinephrine and norepinephrine were measured using a microversion of the trihydroxyindole technique..$^{8,9}$ The pre-induction catecholamine values are consistent with those published by our group ${ }^{10,11}$ and other investigators using this methodology. ${ }^{12,13}$ It should be noted that plasma catecholamine values by the trihydroxyindole technique are consistently higher than those reported using other assays. The reason for this difference is not known. Statistical analysis of the data was done by analysis of variance and the Duncan test. $P<0.05$ was considered to be significant.

Unfortunately no infrared analyzer was available to measure end-tidal isoflurane concentrations. We assume that the end-tidal concentrations reflected the patient's inspired concentrations of $1.5-2.0$ per cent. This assumption is based on the reported closeness of alveolar and inspired concentrations of isoflurane during maintenance anaesthesia. ${ }^{3}$

\section{RESULTS}

Compared to the pre-induction period, cardiac output at period 2 had increased from 3.75 to $4.611 / \mathrm{min}(\mathrm{p}<0.05)$. Heart rate was significantly increased 18 per cent to $80 \mathrm{~b} / \mathrm{min}$. The level of plasma epinephrine was also increased 66 per cent $(p<0.05)$. Conversely, there was a significant decrease in both plasma norepinephrine and systemic vascular resistance index (Figure 1). Mean arterial, diastolic, central venous and pulmonary wedge pressures were slightly lower than their pre-induction values. A significant decrease in systolic blood pressure was observed (Table I). Following stemotomy (period 3) heart rate was still significantly increased at $76 \mathrm{~b} / \mathrm{min}$. Cardiac output and plasma epinephrine levels also remained elevated over pre-induction values, although less than at period 2. The concentration of plasma norepinephrine was $0.76 \mu \mathrm{g} / 1$, which was 30 per cent below the pre-induction value $(\mathrm{p}<0.05)$. Both systemic vascular resistance and systolic blood pressure were still significantly below pre-induction values (Table I).

\section{Discussion}

This study has demonstrated significant changes in sympathoadrenal activity in man 
TABLE I

Haemodynamic and Catecholamine Data

\begin{tabular}{lccc}
\hline \hline & $\begin{array}{c}\text { Period 1 } \\
\text { Pre-Induction }\end{array}$ & $\begin{array}{c}\text { Period 2 } \\
\text { Post-Induction }\end{array}$ & $\begin{array}{c}\text { Period 3 } \\
\text { After Sternotomy }\end{array}$ \\
\hline HR $(\mathrm{b} / \mathrm{m})$ & $67.70 \pm 15$ & $79.70 \pm 11^{*}$ & $76.20 \pm 11^{*}$ \\
CO $(1 / \mathrm{m}$ & $3.75 \pm 1.6$ & $4.61 \pm 1.6^{*}$ & $4.25 \pm 1.2^{*}$ \\
SBP (torr) & $128.40 \pm 7.9$ & $117 \pm 14.2^{*}$ & $109.3 \pm 15.3^{*}$ \\
DBP (tor) & $63.90 \pm 7.5$ & $60.80 \pm 8.2$ & $59.10 \pm 11.5$ \\
XBP (torr) & $85.10 \pm 9.3$ & $78.80 \pm 9.3$ & $75.80 \pm 13$ \\
PCWP (torr) & $9.90 \pm 3.6$ & $8.70 \pm 3.4$ & $9.70 \pm 2.2$ \\
SVRI (dynes $\left.\cdot \mathrm{sec}^{\circ} \mathrm{cm}^{-5} \cdot \mathrm{m}^{2}\right)$ & $3388 \pm 1100$. & $2260 . \pm 700 .^{*}$ & $2609 . \pm 1000 .^{*}$ \\
SWI $\left(\mathrm{g} \cdot \mathrm{m}^{2} / \mathrm{m}^{2}\right)$ & $31.60 \pm 9.3$ & $31.09 \pm 11.3$ & $29.03 \pm 11.9$ \\
EPI $(\mu \mathrm{g} / \mathrm{l})$ & $0.80 \pm 0.22$ & $1.33 \pm 0.65^{*}$ & $0.92 \pm 0.28$ \\
NE $(\mu \mathrm{g} / \mathrm{l})$ & $1.10 \pm 0.16$ & $0.88 \pm 0.38^{*}$ & $0.76 \pm 0.21^{*}$ \\
\hline
\end{tabular}

Mean Values \pm STD. DEV., $N=10$

* Significant compared to Period $1, P<0.05$. Abbreviations used are: HR, heart rate; CO, cardiac output; SBP, systolic blood pressure; DBP, diastolic blood pressure; $\check{X B P}$, mean blood pressure; PCWP, pulmonary capillary wedge pressure; SVRI, systemic vascular resistance index; SWI, stroke work index; EPI, epinephrine; NE, norepinephrine.

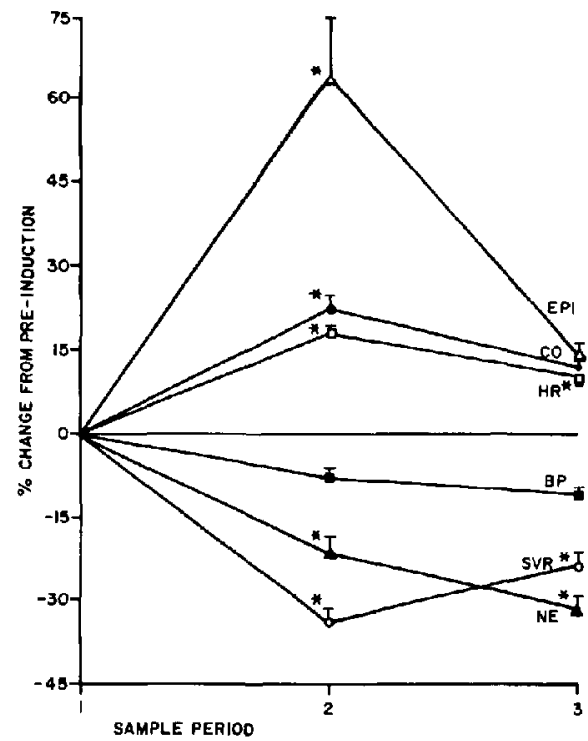

FIGURE 1 Relationship of plasma catecholamines and cardiovascular parameters during isoflurane anaesthesia: 1 , pre-induction control: 2 , after tracheal intubation: 3 , after sternotomy.

$* \mathrm{P}<0.05$ compared to control value

during anaesthesia with isoflurane. The patients had increased plasma epinephrine levels and lowered plasma norepinephrine levels. Although other halogenated inhalation anaesthetics have been shown to influence plasma catecholamine levels, they have not been shown to cause a simultaneous increase in epinephrine and a decrease in norepinephrine. ${ }^{8-11,14,15}$ In addition to the changes in catecholamine levels, significant changes in haemodynamics were noted. The patients in this study had increased heart rate and cardiac output and a marked decrease in peripheral vascular resistance, with only a slight decrease in mean blood pressure. These cardiovascular responses are common to isoflurane in man and have been reported by numerous investigators. ${ }^{1-3,16}$

Changes in plasma catecholamines are considered to reflect sympathoadrenal activity and are associated with changes in haemodynamics. ${ }^{17,18}$ The results obtained in this study suggest that changes in sympathoadrenal activity are related to the cardiovascular responses that occur with isoflurane. Previously, Stevens, et al. ${ }^{1}$ proposed that the increase in heart rate and cardiac output, as well as the decrease in peripheral vascular resistance observed with isoflurane, reflected a beta receptor stimulating property of isoflurane. To date sufficient evidence has not been presented to accept or reject this proposal conclusively, although there has been some supportive evidence, most of which is indirect. ${ }^{2,4,5}$ Merlin ${ }^{19}$ recently reported finding a 57 per cent increase in the level of norepinephrine in coronary venous blood of dogs receiving three per cent isoflurane. He suggested this as evidence for some localized cardiac sympathetic stimulation by isoflurane. Earlier studies measuring cardiovascular responses to beta blockade and isoflurane in dogs could not demonstrate significant cardiac beta stimulation by 
isoflurane, ${ }^{5,6}$ although the results did suggest that isoflurane may possess some peripheral beta receptor activity. Whether results obtained from dogs anaesthetized with isoflurane are entirely applicable to man is not clear. In both man and dog concentrations of isoflurane used clinically cause a decrease in systemic vascular resistance and a small decrease in arterial blood pressure. However, in the dog, isoflurane does not cause the typical sustained tachycardia or increase in cardiac output seen in man. ${ }^{1,19}$

The patients in this study had increased heart rate and cardiac output, as well as decreased systemic vascular resistance, in spite of long term propranolol therapy. The last dose of propranolol was given at midnight the day before operation and the degree of beta blockade was not assessed during operation. Since the cardiovascular responses observed in this study, particularly the tachycardia, were similar to those observed in patients anaesthetized with isoflurane who were not treated with proprano$\operatorname{lol}^{1,16}$ one must conclude that beta block was not complete. In the studies of Philbin and Lowen$\operatorname{stein}^{5,6}$ the dogs received large acute doses of propranolol that caused profound beta blockade. This may explain the absence of cardiac stimulation with isoflurane in their studies.

The finding of increased plasma epinephrine suggests an action of isoflurane on adrenal medullary release of catecholamines. The possjbility that this response represented a sympathetic reflex to lowered blood pressure was ruled out because mean blood pressure declined only six torr, not enough to activate medullary epinephrine release of the magnitude measured.$^{10} \mathrm{We}$ also considered the possibility that the epinephrine increase was due solely to stress associated with tracheal intubation and sternotomy. Plasma epinephrine levels are known to increase with intraoperative stresses. However the levels of epinephrine measured by ourselves and others at identical time periods with halothane, morphine and enflurane anaesthesia are not changed to the extent observed in this study. ${ }^{8-11,20,21}$ Thus the results suggest that the increase in plasma epinephrine reflects an action of isoflurane on adrenal epinephrine release which is over and above the reported catecholamine response to tracheal intubation and sternotomy.

The finding of a reduction in systemic vascular resistance and the levels of plasma norepinephrine in this study suggest an action of isoflurane on peripheral sympathetic activity. We considered other possible causes for the lowered norepinephrine levels. A lowering of plasma norepinephrine has been shown to occur from the awake to the anaesthetized state; however this response is transient. ${ }^{14}$ The use of pancuronium has been shown to lower plasma norepinephrine, but only when there is a concomitant significant increase in rate pressure product. ${ }^{22}$ In this study both plasma norepinephrine and systemic vascular resistance were continually lowered and, although pancuronium was used, the rate pressure product did not change significantly at any of the three study periods. Previously, it was thought that the drop in systemic vascular resistance with isoflurane was due to peripheral beta receptor stimulation.' Our results offer an additional explanation, that isoflurane lowers vascular resistance by diminishing norepinephrine release from sympathetic nerve terminals. Whether this action is mediated centrally or peripherally remains to be shown. The findings of Skovsted and Sapthavichaikul ${ }^{7}$ are consistent with this explanation. They found a reduction in peripheral sympathetic tone and arterial pressure in cats during isoflurane anaesthesia. They proposed that the reduction in sympathetic nervous activity was due to isoflurane-induced depression of pressor neurons of the central vasomotor center, and to a decreased sensitivity of the vascular smooth muscle to sympathetic impulses.

The reported effects of isoflurane on plasma catecholamines are not consistant within the literature. Although some investigations have not demonstrated significant plasma catecholamine changes with isoflurane, ${ }^{23,24}$ these studies mainly used dogs and the variance in results may relate to the differences in cardiovascular responses between dog and man. On the other hand, Dobkin, et al. ${ }^{25}$ reported increased catecholamine levels in non-cardiac patients following isoflurane anaesthesia. They found norepinephrine levels to be increased more than epinephrine. We cannot compare our findings with these results since post-anaesthetic catecholamine levels were not measured in the present study.

In conclusion, this study has demonstrated significant cardiovascular and catecholamine responses with isoflurane. Plasma epinephrine levels increased in conjunction with the increase in heart rate and cardiac output, and plasma norepinephrine levels decreased with the decrease in systemic vascular resistance. The findings suggest that sympathoadrenal responses contribute to the cardiac and peripheral vascular changes observed with isoflurane. 


\section{ACKNOWLEDGEMENT}

The authors would like to express their appreciation to Margaret Kubak, Donald Turner and Mark Hieber for their technical assistance.

\section{REFERENCES}

1. Stevens, W.C., Cromwell, T.H., Halsey, M.J., Eger, E.I, SHAKespeare, T.F. \& BaHLMAN, S.H. The cardiovascular effects of a new inhalation anesthetic, Forane, in human volunteers at constant arterial carbon dioxide tension Anesthesiology 35: 8 (1971).

2. Graves, C.L., McDermott, R.W. \& BidwaI, A. Cardiovascular effects of isoflurane in surgical patients. Anesthesiology 41:486 (1974).

3. EGER, E.I. Isoflurane: A review, Anesthesiology 55: 559 (1981)

4. Horan, B.F., Prys-Roberts, C., Roberts, J.G., BENNETT, M.J. \& FoeX, P. Hemodynamic responses to isoflurane anesthesia and hypovolemia in the dog, and their modification by propranolol. Br. J. Anaesth. 49: 1179 (1977).

5. Philbin, D.M. \& Lowenstein, E. Hemodynamic consequences of the combination of isoflurane anesthesia (1 MAC) and beta-adrenergic blockade in dog. Anesthesiology 42: 567 (1975)

6. PhILBIN, D.M. \& LOWENSTEIN, E. Lack of beta-adrenergic activity of isoflurane in the dog: A comparison of circulatory effects of halothane and isoflurane after propranolol administration Br. J. Anaesth. 48: 1165 (1976).

7. Skovsted, P. \& Sapthavichaikul, S. The effects of isoflurane on arterial pressure, pulse rate, autonomic nervous activity, and barostatic reflexes. Can. Anaesth. Soc. J. 24: 304 (1977).

8. TAN, C.K., Glisson, S.N. \& El-ETR, A.A Circulating norepinephrine and epinephrine levels before, during and after cardiopulmonary bypass in man. J. Thorac. Cardiovasc. Surg. $7 I$ 928 (1976)

9. Balasaraswathi, K., Glisson, S.N., El-Etr A.A. \& Pifarre, R. Serum epinephrine and norepinephrine during valve replacement and aorta-coronary bypass surgery. Can. Anaesth Soc. J. 25: 198 (1978)

10. TaN, C.K., Glisson, S.N., El-Etr, A.A. \& Younes, S.H. Adrenal responses to anesthetics during cardiopulmonary bypass. Cardiovasc Med. 3: 521 (1978).

11. Balasaraswathi, K., Glisson, S.N., El-Etr, A.A. \& AZAD. C. Effect of priming volume on serum catecholamines during cardiopulmonary bypass. Can. Anaesth. Soc. J. 27: 135 (1980)

12. Tammisto, T., JaAttela, A., NkuK, P. \&
TAKKI, S. Effects of pentazocine and pethidine on plasma catecholamine levels. Ann. Clin. Res. 3: 22 (1971)

13. TAKKI, S. \& Tammisto, T. Effects of positive pressure ventilation on plasma catecholamines. Acta. Anaesth. Scand. 17: 238 (1973).

14. Halter, J.B., Pflug, A.E. \& Porte, D. Mechanism of plasma catecholamine increases during surgical stress in man. J. Clin. Endocrin. Metab. 45: 936 (1977)

15. Hoar, P.F., Stone, J.G., Faltas, A.N., BeNDIXEN, H.H. HEAD, R.J. \& BerKowitz, B.A. Hemodynamic and adrenergic responses to anesthesia and operation for myocardial revascularization. J. Thorac. Cardiovasc. Surg. 80 $242(1980)$

16. HOMI, J., KONCHIGERI, H.N., ECKENHOFF, J.E. \& LINDE, H.W. A new anesthetic agent Forane: preliminary observations in man. Anesth. Analg. 51: 439 (1972)

17. Pflug, A.E. \& Halter, J.B. Effect of spinal anesthesia on adrenergic tone and neuroendocrine responses to surgical stress in humans. Anesthesiology 55: 120 (1981).

18. Roizen, M.F., Horrigan, R.W. \& Frazer, B.M. Anesthetic doses blocking adrenergic (stress) and cardiovascular responses to incisionMAC/BAR. Anesthesiology 54: 390 (1981).

19. Merin, R.G. Are the myocardial functional and metabolic effects of isoflurane really different than those of halothane and enflurane? Anesthesiology 55: 398 (1981).

20. Shepard, L.S., Gelman, S., Reeves, J.G. \& OPARIL, $S$. Humoral responses of hypertensive patients to laryngoscopy. Anesth. Analg. 60: 276 (1981).

21. Rolzen, M.F., Moss, J., Henry, D.P. \& KopIN, I.J. Effects of halothane on plasma catecholamines. Anesthesiology 4I: 435 (1974)

22. RoIzen, M.F., Forbes, A.R., Miller, R.D., LAKE, C.R. \& STANSKI, D.R. Similarity between effects of pancuronium and atropine on plasma norepinephrine levels in man. J. Pharm. Exp. Therap. 211: 419 (1979).

23. BYLES, P.H, DOBKIN, A.B., Ferguson, J.H. \& LEvY, A.A. Foranc, (Compound 469): Crossover comparison with enflurane (Ethrane), halothane, and methoxyflurane in dogs. Can. Anaesth. Soc. J. 18: 376 (1971).

24. Perry, L.B., Van Dyke, R.A.\& Theye, R.A. Sympathoadrenal and hemodynamic effects of isoflurane, halothane and cyclopropane in dogs. Anesthesiology 40:465 (1974).

25. Dobkin, A.B., Byles, P.H., Arandia, H.Y. Ghanooni, S., Nishiolka, K. \& Levy, A.A. Comparative metabolic responses to halogenated anaesthetics. Acta. Anaesth. Scand. 16: 69 (1972).

\section{RÉSUMÉ}

Les modifications hémodynamiques ainsi que celles des catécholamines plasmatiques survenant au cours d'anesthésies à l'isoflurane ont été évaluées chez dix patients soumis à des pontages aorto-coronariens. L'induction de l'anesthésie a été effectuée au thiopental et le maintien à l'isoflurane à une concentration de 1.5 à 2 pour cent. Après dix minutes d'anesthésie à l'isoflurane, on observait une augmentation significative de la fréquence 
cardiaque qui passait de 68 à $80 /$ minute, du débit cardiaque qui passait de 3.75 à $4.6 \mu \mathrm{g} / \mathrm{l}$, et de l'épinéphrine plasmatique qui passait de 0.80 à $1.33 \mu \mathrm{g} /$; concouramment, survenait une diminution significative de l'index de résistance vasculaire systémique qui passait de 3388 à 2260 dynes $-\mathrm{sec} \cdot \mathrm{cm}^{-5} \cdot \mathrm{m}^{2}$, et de la norépinéphrine qui s'abaissait à $0.088 \mu \mathrm{g} / \mathrm{l} \mathrm{en}$ comparaison d'un taux de $1.1 \mu \mathrm{g} / \mathrm{l}$ au départ.

Vingt-cinq minutes plus tard, (après la sternotomie) la fréquence, le débit cardiaque et le taux plasmatique d'épinéphrine étaient encore élevés alors que l'index de résistance vasculaire périphérique et le taux plasmatique de norépinéphrine demeuraient abaissés $(\mathrm{p}<$ 0.05). Cette étude démontre la présence d'une réponse significative des catécholamines au cours de l'anesthésie à l'isoflurance. L'élévation de l'épinéphrine plasmatique était parrallèle à l'augmentation de la fréquence et du débit cardiaque alors que la diminution du taux de la norépinéphrine coincidait avec la chute de la résistance vasculaire périphérique. A partir de ces résultats, nous concluons que les modifications des catếcholamines contribuent à la production des modifications cardiaques et vasculaires périphériques observées au cours des anesthésies à l'isoflurane 